\title{
Monitoring Landscape Changes of Rural Townships in the Cold Region of China Using RS, GIS, and Landscape Metrics
}

\author{
Kang-Li Wu ${ }^{1, a}$, Hsing-Fu Kuo ${ }^{2, b}$, Deyu Zhang ${ }^{3, c}$ \\ ${ }^{1}$ Department of Urban Planning, Harbin Institute of Technology, China; Executive Director, HIT-UC \\ Berkeley/IURD Joint Research Center of Sustainable Urban Development; Quemoy University, \\ Taiwan; IURD, UC Berkeley; Corresponding Author \\ ${ }^{2}$ Department of Tourism, Leisure and Hospitality Management, National Chi Nan University, Taiwan \\ ${ }^{3}$ Department of Urban Planning, Harbin Institute of Technology, China \\ aklwu3890302@gmail.com, bluckiekuo@gmail.com, ${ }^{\mathrm{c}}$ deyu1025@163.com
}

Keywords: RS, GIS, Landscape metrics, rural township, cold region

Abstract. Facing the impact of rapid urbanization and the problems of environmental deterioration, how to manage the development of landscape and green spaces in rural townships has become an important issue in China. However, how and to what extent can the patterns and changes of green spaces in the rural townships be identified and analyzed in an efficient and timely way remains an unsolved research question. Using the selected rural township in the cold region of China-the Hutou township - as the case setting, this study explicitly examines the changes of landscape patterns and green spaces by employing Remote Sensing (RS), GIS, and landscape indicators. Through a combination of methods including spatial analysis, GIS mapping, and field survey, this study proposes a methodology for systematically monitoring landscape changes in rural townships. After our empirical investigation, this paper reveals several critical problems of landscape management such as a decrease of landscape diversity and an increase in green space fragmentation in the rural township under study. Accordingly, related suggestions on planning actions and policies are provided to improve the situation.

\section{Introduction}

Landscape is a living entity, representing the results of continuingly interactions between human beings and the environment. Given the trend of rapid urbanization and an increase of rural-to-city immigration in China, how to manage rural townscape development has become a critical issue. In spite of the importance of this issue, however, relatively few research efforts were made to examine the changes of landscape and green spaces in rural townships in China over past decade. Among the many aspects of rural landscape management, how to monitor and manage green space changes is one key issue influencing the biodiversity, living quality, and environmental integrity of many rural townships. Yet, in lack of suitable analytical tools to examine the patterns, structure, and changes of green spaces and landscape in rural townships, many localities have difficulties in implementing sustainable green space planning. In view of this dilemma, this research attempts to explicitly explore two research questions: (1) How to identify the major types and patterns of land cover and green spaces in the rural townships of China using new spatial analytical tools and image data? (2) How to systematically address the changes of landscape patterns and green space structure in order to develop suitable policies for promoting sustainable townscape development. Using the selected rural township in northern China - the Hutou township - as a case setting, this paper proposes a methodology that can be used to manage the development of landscape and green spaces of rural townships. Through the empirical investigation, it is hoped that some critical planning problems can be identified, and related suggestions are useful for planning policies and actions.

\section{Literature Review}

RS, GIS, and landscape metrics are commonly used technologies to address the research issue. Landscape metrics are numeric measurements that quantify the spatial patterns of land cover of a 
geographic area. Previous studies have found that landscape patterns, such as shapes, edges, patch densities, and functions of green corridors and landscape mosaics are related to biodiversity and other ecological values of the environment (see e.g., Dramstad, 1996). Some previous studies also revealed that a disruption in landscape patterns may reduce the functional integrity of an eco-system (e.g., With, 1997). Therefore, how to develop a systematic approach to examine the patterns and changes of landscapes has become an important issue in urban and rural planning. Thanks to the advance of RS and GIS technologies, these new spatial analytical tools provide a useful framework for examining the patterns and structure of landscape and green spaces. Previous studies on this topic can be classified into several categories: (1) Researches use landscape metrics to analyze the changes of land use patterns and landscape fragmentation in land cover (see e.g., Pôças, 2014; Martinez, 2015). (2) Researches employ landscape metrics as indicators to measure the changes of biodiversity or ecological risk. Such as Uuemaa et al. (2014) provided a comprehensive review of current literature which use landscape metrics to measure land use changes, habitat functions, and landscape functions; Schindler et al. (2008) analyzed the landscape structure of Dadia National Park of Greece, and found that the pattern of landscape structure was related to dominating habitat types, land use, and level of protection. (3) Researches use landscape metrics to serve as an assessment tool to address the impact of urban development process on landscape and/or on green spaces. For example, Zhou and Wang (2011) employed an integrated approach and landscape indicators to characterize the changing patterns and intensities of green spaces in Kunming of China from 1992 to 2009 in response to rapid urbanization. Tian et al. (2014) used the landscape patterns of urban green spaces (UGS) in Hong Kong to analyze the ecological quality of landscape in different land uses and districts. Their study found that some old districts had smaller and more heterogeneous UGS than newer ones, due to relatively low-quality landscape attributes.

\section{Research Design}

The Hutou Township, one of the typical rural township in the cold region of China, is selected as the case setting of this study. The township is located in the Hutou county by the east part of Wusuli Riverside in Hulin City, Heilongjiang Province, looking to the Дальнере́ченск Сity of Russia across the river (Fig. 1). This region had possessed abundant natural green resources and comfortable living environment; however, under the impacts of unmanaged land development, some of the landscape patterns and green spaces are affected. Therefore, how to systematically monitor the changes of landscape patterns and green space structure has become a critical issue for the management of regional landscape. This research integrates a number of research methods, including field survey, RS and GIS spatial analysis, calculating landscape indicators, and land use mapping. Data used include the 2004 Landsat 7 and the 2014 Landsat 8 remotely sensed images, GIS green space maps, Google maps, and field survey data. ENVI 5, ArcGIS 10, and Patch Analyst 5.1 for ArcGIS software were used in the analysis. The procedure of data analysis is shown in Fig 2, and the selected landscape indicators used in the analysis are summarized in Table 1.

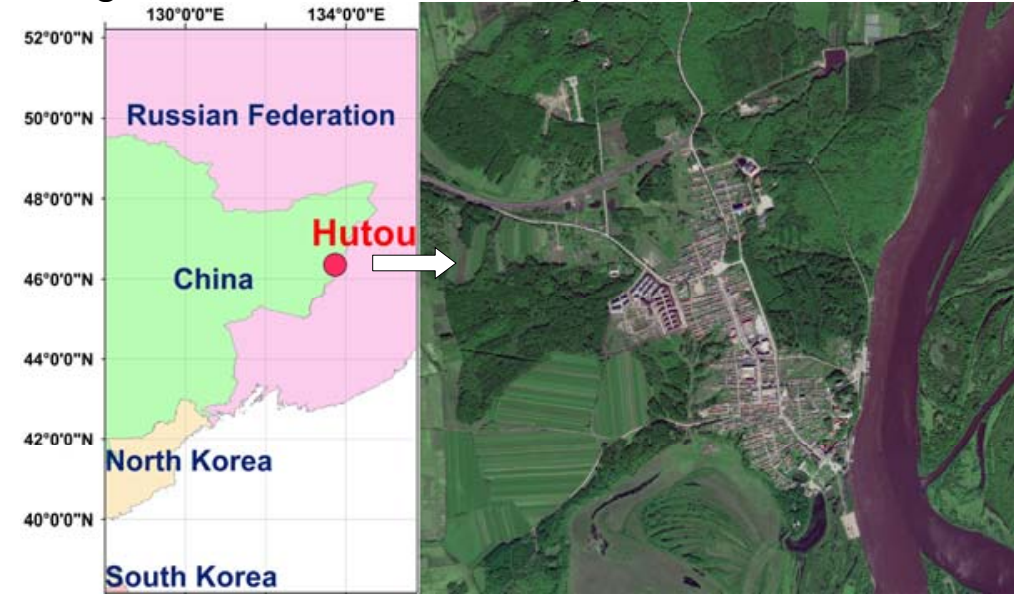

Fig. 1 The location and study area of Hutou

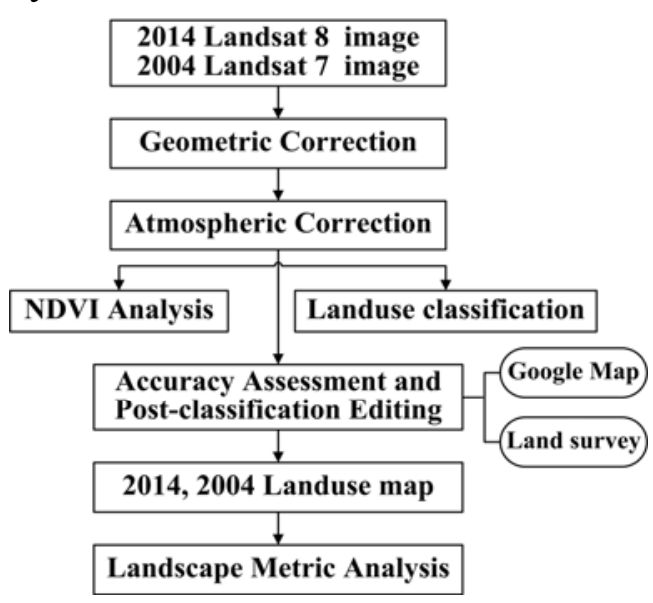

Fig.2 Data analysis procedure 
Table1. Landscape metrics used in this study

\begin{tabular}{|c|c|c|}
\hline Indicator & $\begin{array}{l}\text { Type of } \\
\text { Analysis }\end{array}$ & Description \\
\hline $\begin{array}{l}\text { Area Weighted Mean Shape Index } \\
\text { (AWMSI) }\end{array}$ & Diversity & $\begin{array}{l}\text { Shape complexity adjusted for shape size; equals the sum, across } \\
\text { all patches in the landscape, of the means shape index multiplied } \\
\text { by the proportional abundance of the patch }\end{array}$ \\
\hline Edge Density (ED) & Diversity, Frag. & Amount of edge relative to the landscape area \\
\hline Mean Perimeter-Area Ratio (MPAR) & Diversity & The sum of all perimeters divided by the total area \\
\hline Mean Patch Edge (MPE) & Diversity, Frag. & Average amount of edge per patch \\
\hline Mean Shape Index (MSI) & Diversity & $\begin{array}{l}\text { Sum of patch's perimeter divided by the square root of patch area } \\
\text { for all and adjusted by a square standard, then divided by total No. }\end{array}$ \\
\hline Total Edge (TE) & Diversity, Frag. & Perimeter of patches \\
\hline Mean Patch Size (MPS) & Fragmentation & Average patch size \\
\hline Median Patch Size (Med PS) & Fragmentation & The middle patch size, or 50th percentile \\
\hline Patch Size Coefficient of Variance (PSCoV) & Fragmentation & Coefficient of variation of patches \\
\hline Patch Size Standard Deviation (PSSD) & Fragmentation & Standard Deviation of patch areas \\
\hline Number of Patch (NumP) & Fragmentation & Total number of patches in the landscape \\
\hline
\end{tabular}

\section{Research Result}

The data analysis of this study includes several steps (see Fig. 2). First, the 2004 and 2014 images were geo-referenced to the UTM coordinate system using the ENVI software. Eighteen ground control points were used for geometric correction. Atmospheric correction was then conducted. To identify the basic patterns of land cover and green spaces, NDVI analysis and several classification methods, including supervised classification, unsupervised classification, and the principal component analysis were used. NDVI analysis was used to help identify the green resources, and a threshold of 0.2 was used to build green space polygons. The green space polygons were then compared with the image classification results to help identify the basic types of land cover and green spaces. Post-classification editing with field survey data and NDVI results were also conducted to correct the classification errors. Using the maximum likelihood classifier, six land use categories are identified, including built-up land (including residential, commercial, industrial, and transportation land etc.); water (rivers, lakes, etc.); forest land (deciduous, evergreen and mixed forest, etc.); farm land; grass land (gardens, parks with low tree density, etc.), and barren land. Fifty sampling points for each land use class were selected to assess the classification accuracy. The overall accuracy of the 2014 image is $81.2 \%$, and the overall accuracy of the 2004 image is $78.9 \%$. In the next step, Google maps and the land survey data were used to conduct the post-classification editing and create the final land use map. The results are shown in Fig 3 and Fig. 4.

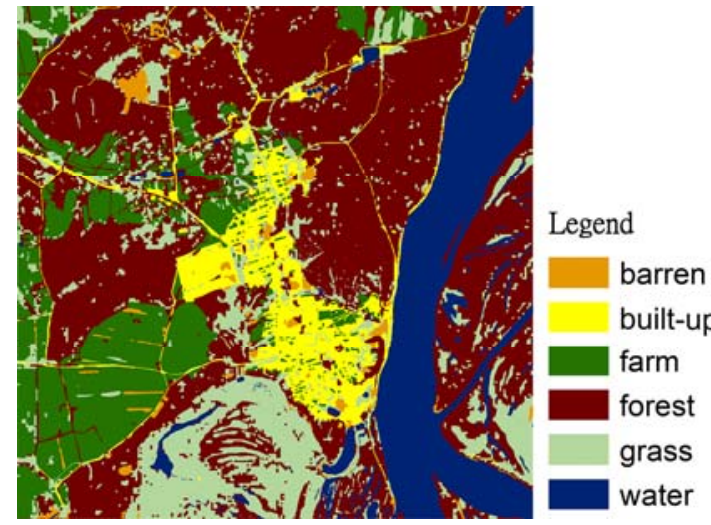

Fig.3 Land use of Hutou (2004)

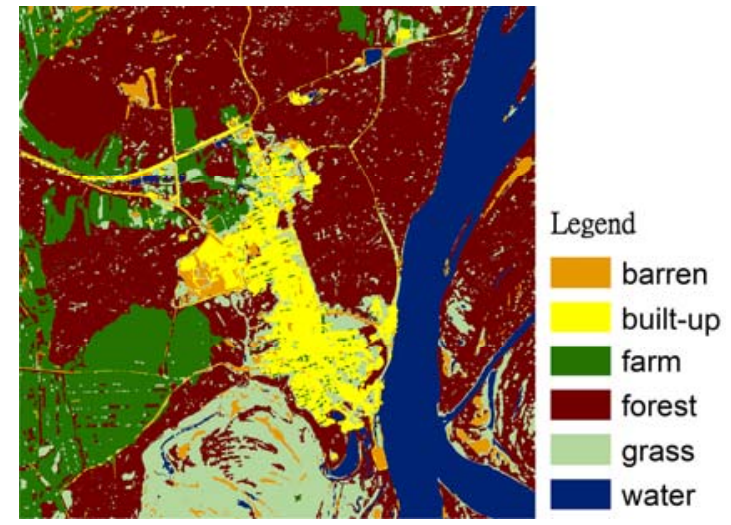

Fig.4 Land use of Hutou (2014)

As shown in Fig.4, in Hutou, forest land covers the largest area (47.11\%), followed by grass land (14.38\%), water spaces (13.98\%), farm land (13.97\%), build-up land (7.35\%) and barren land (3.21\%). Barren land increased between 2004 and 2014 due to land development and changes of land use, while water spaces decreased in certain areas in and around grass land. The classification results of 2004 and 2014 were then converted into raster format for calculating landscape indicators using Patch Analyst 5.1. Eleven selected indicators (Table 1) were calculated including indicators measuring the characteristics of patch density, shape, diversity, and fragmentation of landscape. 
Table 2. Result of landscape metrics analysis

\begin{tabular}{|c|c|c|c|c|c|c|c|c|c|c|c|c|}
\hline Class & Year & AWMSI & ED & MPAR & MPE & MSI & TE & MPS & MedPs & PSCoV & PSSD & NumP \\
\hline \multirow[t]{2}{*}{ barren } & 2014 & 2.35 & 57.00 & 8984.14 & 111.78 & 1.60 & 76907.66 & 0.06 & 0.01 & 333.58 & 0.21 & 688.00 \\
\hline & 2004 & 1.68 & 17.91 & 4863.98 & 133.58 & 1.48 & 24310.75 & 0.11 & 0.03 & 272.52 & 0.30 & 182.00 \\
\hline \multirow[t]{2}{*}{ building } & 2014 & 14.46 & 69.96 & 30336.42 & 273.58 & 2.1 & 94385.69 & 0.29 & 0.01 & 1565.13 & 4.50 & 345.00 \\
\hline & 200 & & 72. & & 438 & 1. & 990 & & 2 & 61 & 5.96 & 26.00 \\
\hline \multirow[t]{2}{*}{ farm } & 201 & & 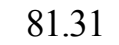 & 15 & 306.43 & 1.79 & 10 & 0. & 0.01 & 10 & 39 & $8 .(\mathrm{C}$ \\
\hline & 200 & 2.02 & 72.09 & 2 & 19 & $1.4 \quad \mathrm{C}$ & 978 & 0. & 0.04 & 51 & 2.00 & 494.00 \\
\hline \multirow[t]{2}{*}{ forest } & 2014 & 13.09 & 7.04 & 55710.22 & 284.33 & 2.2 & 535669.44 & 0. & 00 & 1600.12 & 5.40 & 1884.00 \\
\hline & 2004 & 8.33 & 3.56 & 119 & 878.50 & 2.06 & 26267 & 2.0 & 0.05 & 703.46 & 14.49 & 299.00 \\
\hline \multirow[t]{2}{*}{ grass } & 2014 & 6.42 & 206.61 & 14651.87 & 93.48 & 1.49 & 278752.01 & 0.07 & 0.01 & 2454.00 & 1.60 & 2982.00 \\
\hline & 2004 & 51 & 153.82 & 60 & 152.04 & 1.54 & 208747.56 & 0.16 & 2 & 1390.53 & 2.21 & 1373.00 \\
\hline \multirow[t]{2}{*}{ water } & 201 & 4.08 & 28.61 & 170 & 250 & 1.6 & 3860 & 1.22 & 0.01 & 1153.34 & 14.12 & 154.00 \\
\hline & 2004 & 2.89 & 33.99 & 3486.80 & 257.71 & 1.59 & 46130.00 & 1.13 & 0.04 & 1148.67 & 13.02 & 179.00 \\
\hline
\end{tabular}

As shown in Table 2, one can notes that some of the land use patterns of Hutou township have been changed in the past decade. The number of patches and the amount of barren land, for example, have grown rapidly, while the diversity of landscape and green spaces was reduced, both in built-up areas and in surround natural areas. Consistent with several other related studies, our research shows a trend of increase in landscape fragmentation and decrease in the green space diversity which may subsequently affect the bio-diversity and ecological function of the region.

\section{Conclusions}

This study finds several problems of landscape management of rural townships in China, including an increase in the fragmentation of landscape and green spaces, and losses of green space diversity in accompany with land-use changes of the township. The results also reveal that the multiple-temporal analysis integrated with RS, GIS, and field survey provides an operational tool for analyzing the relationship between landscape changes and land development in rural townships. Given that the problems of landscape fragmentation and loss of green space diversity identified in this study, the results reveal that more comprehensive green space policies and planning actions are necessary in order to mitigate the impact of land development on the landscape of rural townships.

\section{Acknowledgements}

This research is funded by National Technological Support Project of China. Project No: 2013BAJ12B02

\section{References}

[1] Dramstad, W. E., J. D. Olson, and R. T.T. Forman. 1996. Landscape Ecology Principles in Landscape Architecture and Land-Use Planning. Washington D. C.: Island Press.

[2] Martinez del Castillo, E., A. Garcia-Martin, L. A. Longares Aladren and M. de Luis. 2015. Evaluation of forest cover change using remote sensing techniques and landscape metrics in Moncayo Natural Park (Spain), Applied Geography, 62, 247-255.

[3] Pôças, Isabel, Mario Cunha, Luis S. Pereira. 2011. Remote sensing based indicators of changes in a mountain rural landscape of Northeast Portugal. Applied Geography, 31(3), 871-880.

[4] Schindler, S., K. Poirazidis and T. Wrbka. 2008. Towards a core set of landscape metrics for biodiversity assessments: A case study from Dadia National Park, Greece, Ecological Indicators, 8(5), 502-514.

[5] Tian, Y., C. Y. Jim and H. Wang. 2014. Assessing the landscape and ecological quality of urban green spaces in a compact city, Landscape and Urban Planning, 121, 97-108.

[6] Uuemaa, Evelyn, Ülo Mander and Riho Marja. 2014. Trends in the use of landscape spatial metrics as landscape indicators: a review. Ecological Indicators, 28, 100-106. 
[7] With, Kimberly A. 1997. The application of neutral landscape models in conservation biology. Conservation biology, 11(5), 1069-1080.

[8] Zhou, X-L \& Y-C Wang. 2011. "Spatial-temporal dynamics of urban green space in response to rapid urbanization and greening policies." Landscape and Urban Planning 100(3), 268-277. 